Vital verifiable CPD - INSTRUCTIONS

Vital verifiable CPD was launched in the summer 2008 issue of Vital. It offers DCPs the opportunity to complete eight hours of verifiable CPD per year for £30 (+VAT), by reading Vital articles either in their free copy of Vital, or by accessing our website at www.nature.com/vital to read the articles for free there.

Vital CPD is only available via our website.

CPD for UK DCPs began on 1 August 2008. From this date it is a legal requirement for all registered dental care professionals (DCPs) to keep a record of all verifiable and non-verifiable (general) CPD hours.

It is free to access all Vital articles (past and present) on our website as long as you register to obtain a free account. You will need your own email address to register; you may encounter problems if you use an address shared with other people. Free email accounts are widely available on the Internet, for example at www.hotmail.co.uk and www.yahoo.co.uk.

\title{
INSTRUCTIONS
}

1. To register to obtain a free account on the Vital website:

- Go to www.nature.com/vital

- In the top right hand corner of the screen it says 'register' Click here and enter your details to obtain an account for free.

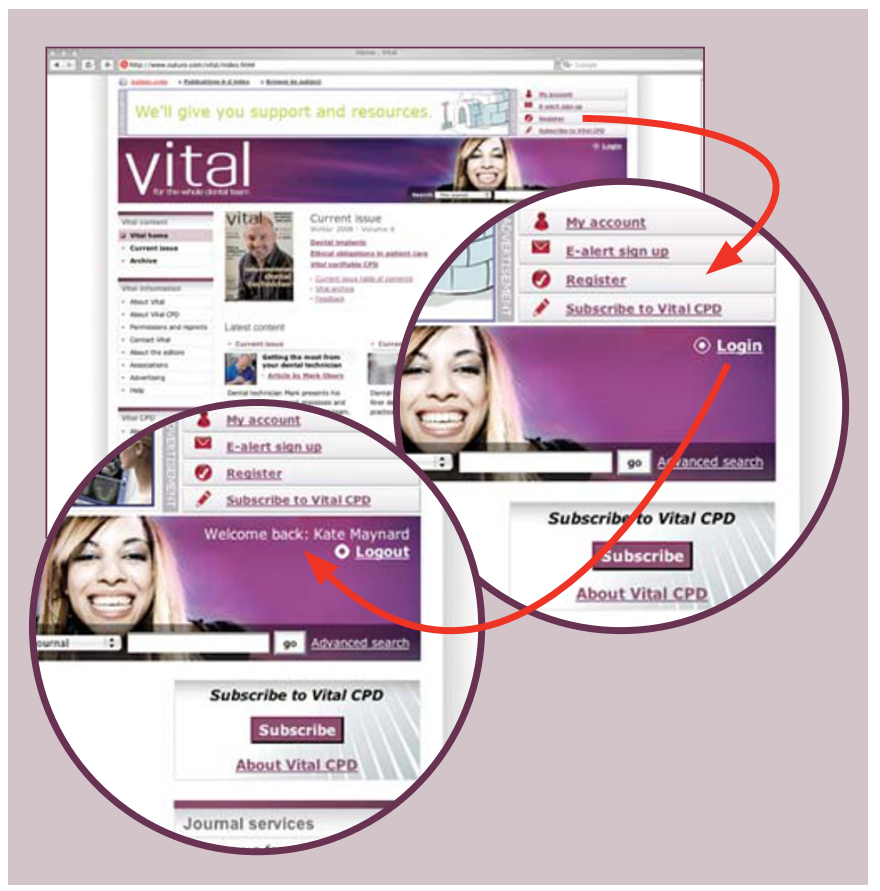

2. Log-in with your user name and password. It will say 'Welcome back: (your name)' at the top of the Vital homepage.
3. To subscribe to Vital CPD:

- Click on the button on the Vital website that says 'Subscribe to Vital CPD' or go directly to: www.nature.com/vitalcpd

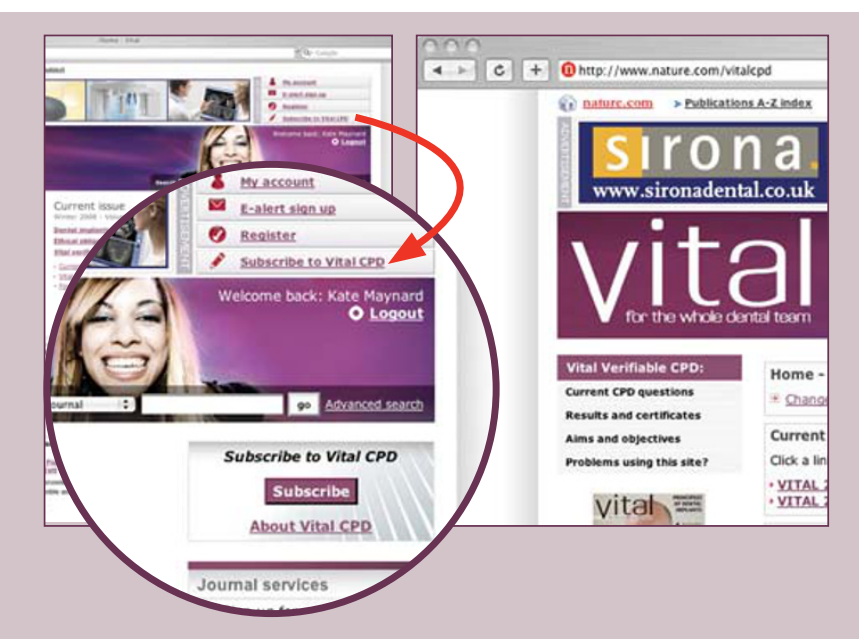

4. Click on 'subscribe now'.

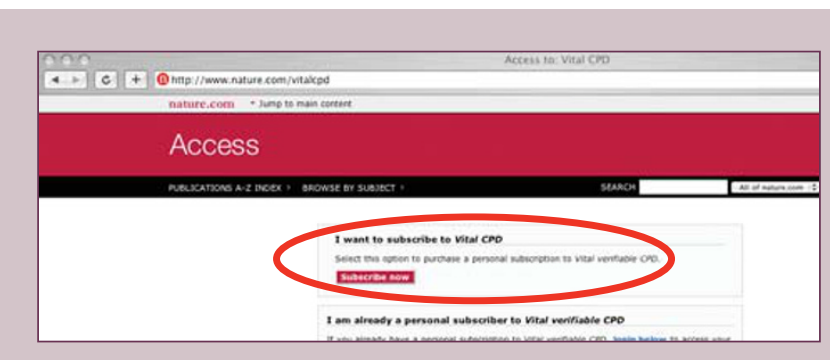


- Select 'I live in the United Kingdom' from the box at the top then follow the payment instructions

- After successfully purchasing your subscription online you will be emailed a temporary customer ID number which will be something like 'EC12345'.

5. When you have received your temporary customer ID number, return to the Vital homepage www.nature.com/vital (make sure you are logged in) and click on 'My Account' in the top right hand corner.

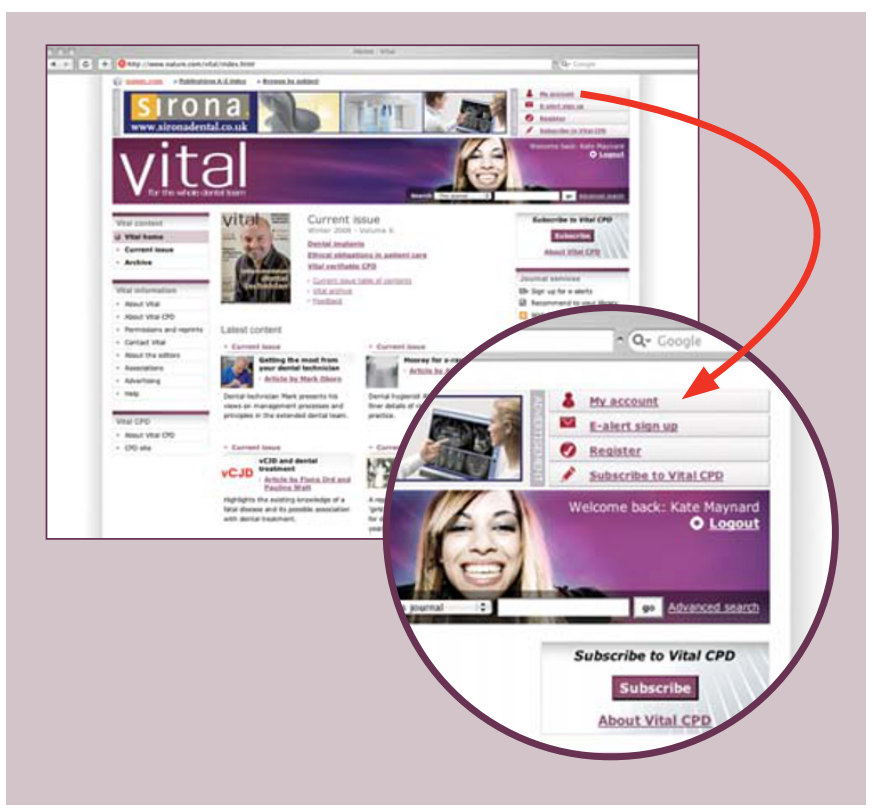

- Click on the tab that says 'subscriptions' at the top

- Enter your customer ID number beginning 'EC' and click on 'confirm' (you only need to do this once) to associate your CPD subscription with your Vital account.

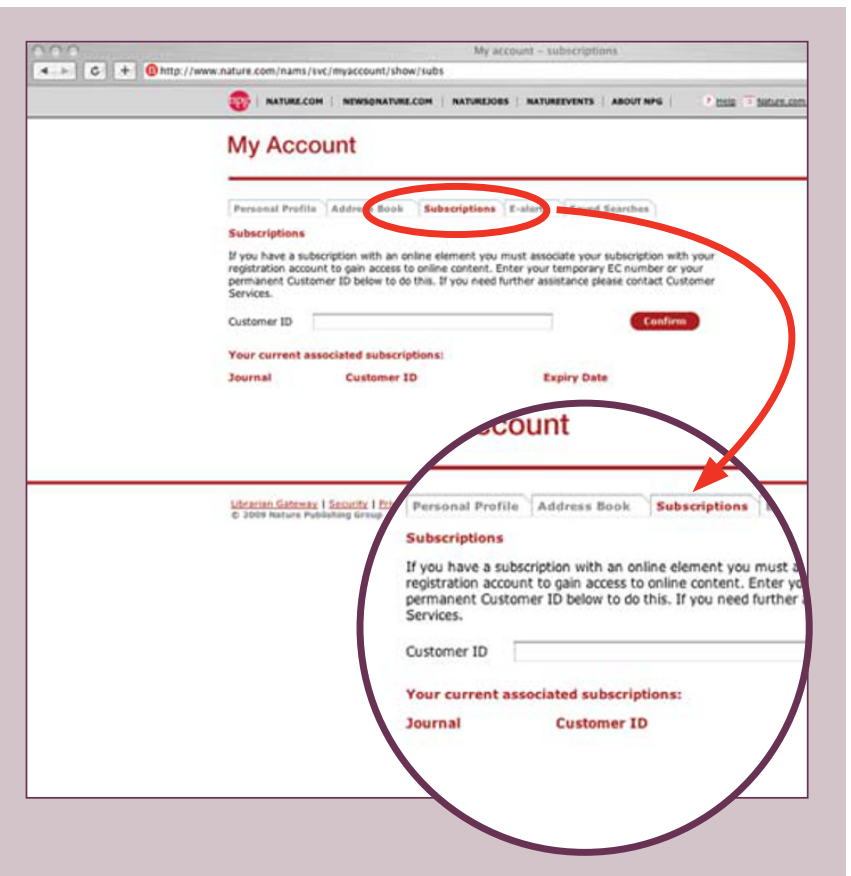

6. You are now ready to access Vital CPD. Click on 'CPD Site' on the homepage at www.nature.com/vital or go directly to www.nature.com/vitalcpd.

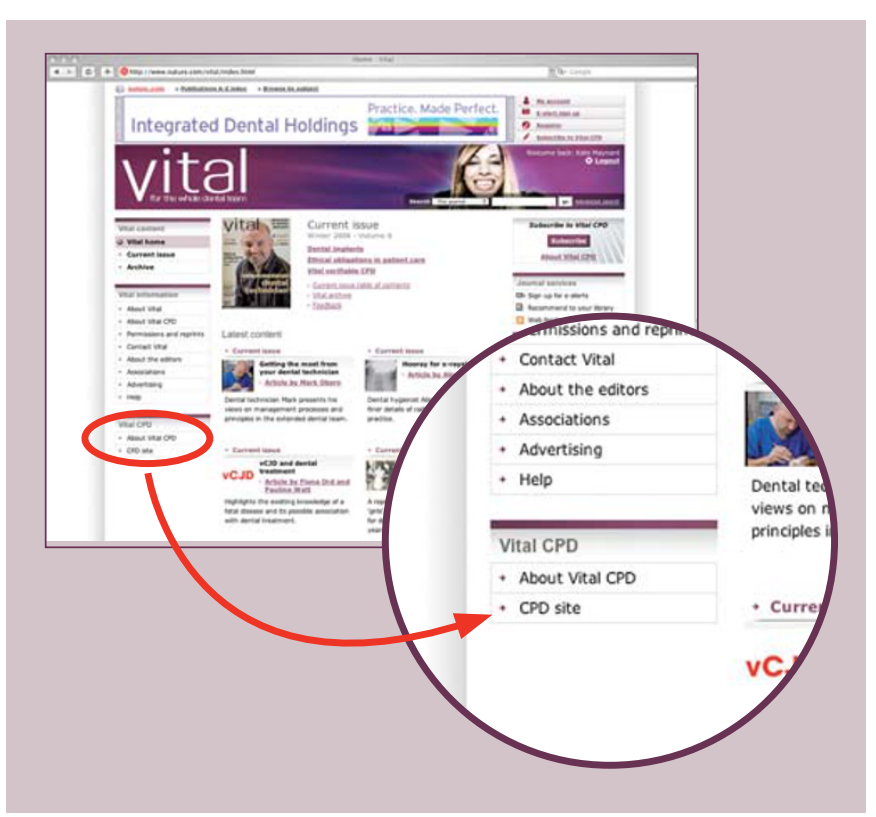

When you are on the Vital CPD website, there is a link at the top through which you can enter your GDC registration number (if you have one - unregistered DCPs are also welcome to take part in Vital CPD). This will ensure that it is included on your CPD certificate when you come to printing it off.

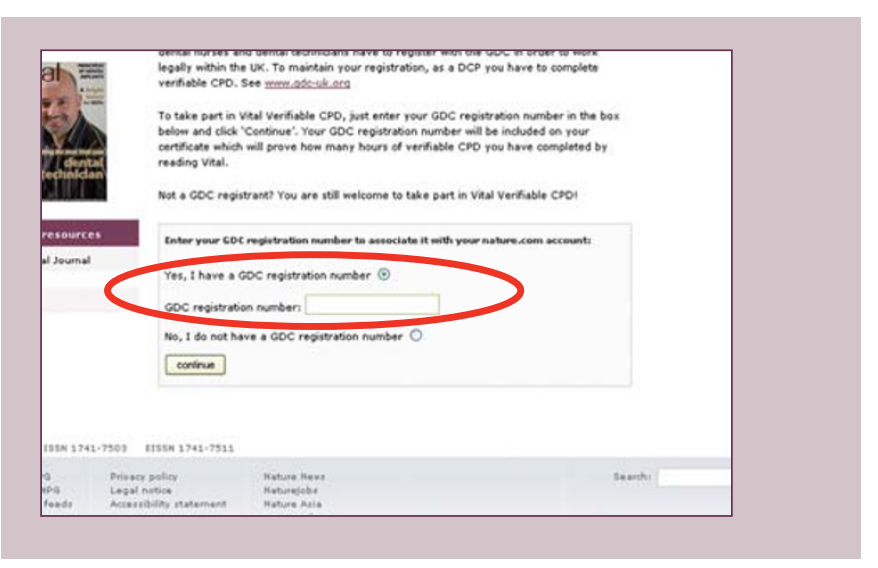

Important note: After your payment has been processed by Vital's publishers, Nature Publishing Group, you will be sent a permanent customer ID number. You will then need to access your account once more and enter your new number into the subscriptions box - as described in point 5. Please keep an eye on your email until you have received your permanent customer ID number, or you may not be able to access the next set of CPD questions.

If you have any problems, email subscriptions@nature.com and you will receive assistance within 24 hours. Send any general queries to vitaleditorial@nature.com. 


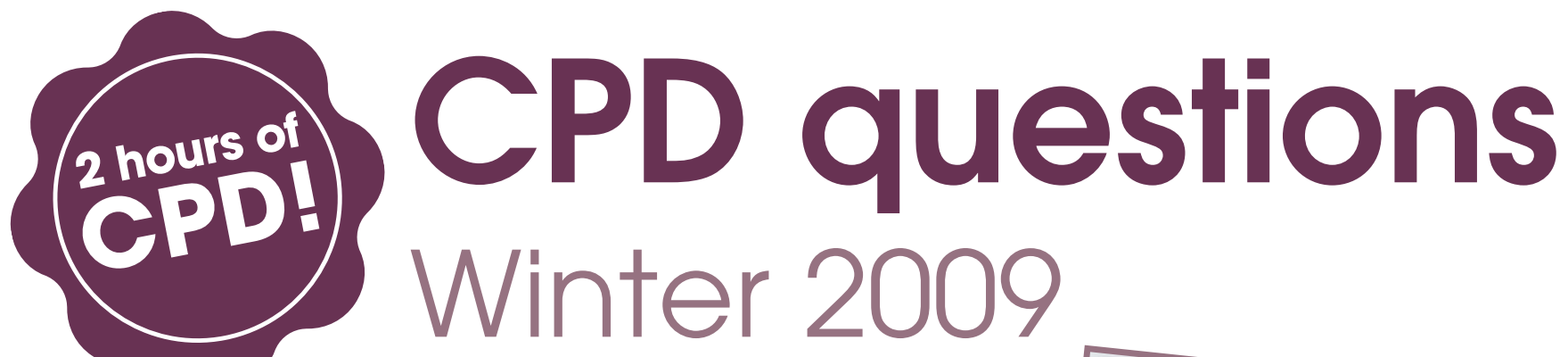

CPD ARTICLE 1 - PAGES 21-23

\section{Clinical governance and the dental team}

1. Which statement is true?

A. health care is still delivered with no reference to the patient

B. clinical governance is not relevant to some members of the dental team

C. informed consent is now an ethical responsibility for the whole dental team

D. clinical governance only applies to dental care provided by the NHS

2. NICE:

A. has produced guidance on the use of prophylactic antibiotics

B. has had a large input into dentistry so far
C. advises on the organisation of NHS services

D. is responsible for the protection of the patient by setting standards

3. Quality improvement in delivering standards includes:

A. using clinical indicators as a measure of performance

B. undertaking evidence-based practice

C. reviewing one's own clinical practice

D. all of the above

A. only b) is correct

B. b) is incorrect

C. only a) is correct

D. only c) is correct

4. CPD: a) is lifelong learning; b) always involves formal studies; c) can help prevent complacency and inertia

\section{CPD ARTICLE 2 - PAGES 43-46}

\section{Vital guide to radiography and radiation protection}

1. Operators should seek to ensure that all dental exposures are:

A. as high as reasonably practicable

B. justified

C. free from radiation risk

D. all of the above

2. Which of the following is false? Radiation dose to patients may be reduced by:

A. avoidance of routine radiographic screening prior to clinical examination

B. use of $E$ speed rather than $F$ speed film

C. restricting the area exposed to only the area of interest

D. a well organised quality assurance programme

3. Select the incorrect statement.

A. IR(ME)R 2000 defines the role

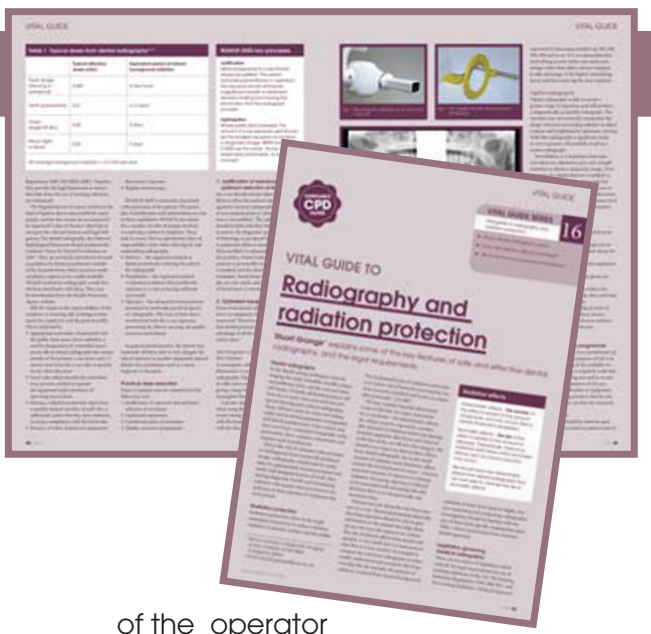

of the operator

B. IR(ME)R 2000 stipulates the requirement for controlled areas

C. IRR99 stipulates the requirement for a radiation protection supervisor

D. IR(ME)R 2000 requires the principle of optimisation to be employed

4. Careful radiographic technique includes:

A. explanation of the procedure to the patient
B. immobilisation of the head

C. regular audit

D. $A$ and $B$

To submit your answers, please see the instructions on the previous page. The deadline for submission of this set of answers is 5 March 2010.

\section{CPD ANSWERS - AUTUMN}

Answers to the CPD questions in the autumn 2009 issue of Vital.
Q1. B
Q1. B
Q3. $B$
Q4. A

\section{Complaints procedures explain \\ Q1. C \\ Q2. D \\ Q3. B \\ Q4. D}

